\title{
Electro-optical missile plume detection
}

\author{
Filip Neele*, Ric Schleijpen** \\ TNO Physics and Electronics Laboratory, The Hague, The Netherlands
}

\begin{abstract}
Missile warning systems operating in the ultraviolet part of the spectrum have become a common part of the suite of self-defence systems of modern aircraft. These systems have a low false alarm rate and a detection range of several kilometres against man-portable surface-to-air missiles. The performance of the missile warning systems depends on several factors, including weather and threat type. This paper uses a generic missile warning sensor and a recently developed model to predict missile plume UV radiance, to demonstrate the variability in detection range for a number of typical threats, weather types, aircraft speeds and warning system lay-outs. The variation in sensor performance present in the results shows that an assessment of the level of platform self-protection prior to each mission should be performed.
\end{abstract}

Keywords: UV, missile signatures, missile warning systems

\section{INTRODUCTION}

To counter the threat of infrared-guided missiles, many nations have equipped their aircraft with a suite of selfprotection systems, with a missile warning sensor operating in the ultraviolet (UV) part of the spectrum. The detection range of these sensors is limited, several kilometres against man-portable surface-to-air missiles, but their false-alarm level is low. The use of infrared sensors, which have a potentially much longer detection range, is limited, due to the more complex image processing needed to extract the missile target from its background.

The low false-alarm rate of the UV sensors is due to absence of background radiation and, in general, the absence of sources of UV radiation. In the wavelength band of these sensors, $250-290 \mathrm{~nm}$, no solar radiation reaches the Earth's surface, as it is absorbed by atmospheric ozone. Ozone also absorbs radiation from the missile plume, which limits detection ranges for portable surface-to-air missiles to several kilometres.

The detection range depends on a number of parameters, one of which is the propellant type of the threat missile. Currently widespread aluminised, high-thrust propellants generate plumes that strongly emit UV radiation, but lowvisibility propellants have already been developed. The ozone concentration is a second parameter that affects system performance. Especially during summer in industrial areas, the ozone concentration can reach high values, further limiting the performance of the missile warning sensors.

Using a model for the UV emission from missile plumes developed recently ${ }^{1}$, the performance of a UV missile sensor is shown against several threat types, in different atmospheric conditions and for a number of sensor lay-outs on the platform. The threat types considered include propellants that produce high-intensity and low-intensity exhaust plumes; the results show that UV sensors are insufficient against low-visibility threats, once they become operational. It is shown that the detection range increases strongly with increasing platform speed for most threat directions. This is because the threats mostly use proportional navigation, and at increasing platform speeds an increasingly larger part of the plume becomes visible behind the missile body.

\footnotetext{
*neele@fel.tno.nl; phone +31 70374 0461; fax +31 703740654

**schleijpen@fel.tno.nl; phone +31 70374 0045; fax +31 703740654

TNO Physics and electronics laboratory, P.O. Box 96864, 2509 JG Den Haag, The Netherlands
} 
At this point, all elements are available to allow missile warning sensor performance to be evaluated in an operational setting. Tools can be developed to include the level of platform self-protection in mission planning, thus increasing the survivability of crew and aircraft.

\section{METHODOLOGY}

\subsection{Propellants}

Four different propellant types were considered, from high-intensity and high-thrust propellants to low-intensity fuels. The exhaust plumes were computed from the composition, temperature and pressure of the exhaust gases at the exit plane; the propellants used were copied from those given by Rapanotti et al. $^{2}$. The first propellant type, HTPB-AP-Al, is a widespread solid propellant that generates high thrust, as well as a high-intensity plume, at both UV and IR wavelengths. The aluminium that is added to the propellant to increase thrust causes the high intensity, through the high temperature of the exhaust gases. The aluminium is present in the plume in the form of $\mathrm{Al}_{2} \mathrm{O}_{3}$ particles, which generate a significant amount of UV radiation. The low-intensity variants of the HTPB-AP propellant are HTPB-AP (containing no aluminium) and HTPB-AP-HB (high burn rate fuel). The fourth propellant, glycidyl acide polymer and ammonium nitrate, is a propellant that finds its application in areas where low-temperature combustion is required ${ }^{2}$. It can be expected that propellants such as GAP-AN will also find their application in low-visibility missiles ${ }^{2}$.

The nozzle radii in Table 1 were set to produce a thrust of $1 \mathrm{kN}$ for each propellant type, which is a representative value for man-portable surface-to-air missiles. This value is the order of magnitude thrust for a missile with a weight of $5 \mathrm{~kg}$ and a maximum speed of $500 \mathrm{~m} / \mathrm{s}$, which it obtains within $2.5 \mathrm{~s}$.

Table 1. Parameters for plume structure and composition modelling ${ }^{2}$. Nozzle radius is adjusted for each propellant to achieve the a thrust of $1 \mathrm{kN}$ for all propellants.

\begin{tabular}{|c|c|c|c|c|}
\hline & HTPB-AP-Al & HTPB-AP & HTPB-AP-HB & GAP/AN \\
\hline Exit radius [mm] & 16.2 & 16.3 & 13.2 & 23.2 \\
\hline Axial velocity [m/s] & 2404.6 & 2388.1 & 2205.8 & 2292.4 \\
\hline Radial velocity $[\mathrm{m} / \mathrm{s}]$ & 356.7 & 354.2 & 327.2 & 340.0 \\
\hline Exit pressure $[\mathrm{kPa}]$ & 200.4 & 168.7 & 420.3 & 57.6 \\
\hline Exit temperature $[\mathrm{K}]$ & 2327.2 & 1578.0 & 1783.3 & 689.4 \\
\hline \multicolumn{5}{|c|}{ Exit plane mole fractions } \\
\hline $\mathrm{N}_{2}$ & $8.151 \times 10^{-2}$ & $9.912 \times 10^{-2}$ & $9.852 \times 10^{-2}$ & $2.517 \times 10^{-1}$ \\
\hline $\mathrm{CO}$ & $2.106 \times 10^{-1}$ & $6.745 \times 10^{-2}$ & $7.752 \times 10^{-2}$ & $1.344 \times 10^{-1}$ \\
\hline $\mathrm{H}_{2} \mathrm{O}$ & $1.368 \times 10^{-1}$ & $4.212 \times 10^{-1}$ & $4.266 \times 10^{-1}$ & $3.943 \times 10^{-1}$ \\
\hline $\mathrm{CO}_{2}$ & $1.713 \times 10^{-2}$ & $1.537 \times 10^{-1}$ & $1.456 \times 10^{-1}$ & $7.773 \times 10^{-2}$ \\
\hline $\mathrm{H}_{2}$ & $2.985 \times 10^{-1}$ & $6.370 \times 10^{-2}$ & $6.085 \times 10^{-2}$ & $1.390 \times 10^{-1}$ \\
\hline $\mathrm{H}$ & $4.094 \times 10^{-3}$ & $8.000 \times 10^{-6}$ & $3.700 \times 10^{-5}$ & $1.090 \times 10^{-4}$ \\
\hline $\mathrm{OH}$ & $3.210 \times 10^{-4}$ & $2.000 \times 10^{-6}$ & $1.700 \times 10^{-5}$ & $3.800 \times 10^{-5}$ \\
\hline $\mathrm{O}_{2}$ & $1.000 \times 10^{-6}$ & $1.000 \times 10^{-8}$ & $1.000 \times 10^{-8}$ & $1.000 \times 10^{-8}$ \\
\hline $\mathrm{O}$ & $3.000 \times 10^{-6}$ & $1.030 \times 10^{-8}$ & $1.000 \times 10^{-8}$ & $1.000 \times 10^{-8}$ \\
\hline $\mathrm{HO}_{2}$ & $1.000 \times 10^{-8}$ & $1.000 \times 10^{-8}$ & $1.000 \times 10^{-8}$ & $1.000 \times 10^{-8}$ \\
\hline $\mathrm{Cl}$ & $1.552 \times 10^{-3}$ & $2.000 \times 10^{-5}$ & $8.800 \times 10^{-5}$ & \\
\hline $\mathrm{Cl}_{2}$ & $1.000 \times 10^{-6}$ & $1.000 \times 10^{-8}$ & $1.000 \times 10^{-8}$ & \\
\hline $\mathrm{HCl}$ & $1.576 \times 10^{-1}$ & $1.929 \times 10^{-1}$ & $1.863 \times 10^{-1}$ & \\
\hline $\mathrm{Al}_{2} \mathrm{O}_{3}$ & $9.065 \times 10^{-2}$ & & & \\
\hline $\mathrm{MgO}$ & & & & $2.661 \times 10^{-3}$ \\
\hline
\end{tabular}




\subsection{Plume signature codes}

The UV emission from the four plumes was computed with UVPLUME $^{1}$. This code computes the CO-O chemiluminescence in the exhaust plume, which is the dominant source of UV emission at wavelengths below about $300 \mathrm{~nm}$. Aluminium particles in the plume emit UV, and, more importantly, cause scattering inside the plume. This raises the total radiant intensity of the HTPB-AP-Al plume by only about $10 \%$ at side-on view, but this scattering process is more important for near nose-on views. At these aspect angles, the missile body hides the most intense parts of the plume from view and only the outer, relatively cold plume layers are visible. Scattering at the aluminium particles of the radiation from the hot core towards the observer significantly increases the visibility of the plume. Ignoring the scattering would lead to an underestimation of plume visibility at nose-on views by a factor of almost five, for the HTPB-AP-Al plume.

The plume emission code has been validated with plume radiance measurements, for both static and dynamic conditions. The reader is referred to ref. 1 for a detailed description of the code and validation. Plume flowfields, which are needed as input for the plume radiance code, were computed with the REP model ${ }^{3,4}$.

\subsection{Missile warning sensor}

A generic sensor was used to represent real UV missile warning sensors. The generic sensor is assumed to be sensitive in the wavelength band $270-290 \mathrm{~nm}$, which is in the solar-blind wavelength band. The sensor is assumed to be in photon-counting mode, which allows a straightforward computation of the detection threshold. Assuming a minimum signal-to-noise ratio of 5 , the detection threshold is computed to be $1.2 \cdot 10^{-15} \mathrm{~W} / \mathrm{cm}^{2}$. Table 2 lists the parameters that were used to derive this threshold. It is assumed that the full frame time is used to collect signal.

Table 2. Parameters used for the generic missile warning sensor.

\begin{tabular}{|l|l|}
\hline Sensor parameter & Value \\
\hline Wavelength band & $270-290 \mathrm{~nm}$ \\
Optics aperture radius & $\varnothing 3 \mathrm{~cm}$ \\
Filter transmission & $20 \%$ \\
Quantum efficiency & $7 \%$ \\
Frame rate & $25 \mathrm{~Hz}$ \\
Detection threshhold & $1.2 \times 10^{-15} \mathrm{~W} / \mathrm{cm}^{2}$ \\
\hline
\end{tabular}

\subsection{Amospheric propagation}

The atmospheric effects are accounted for through the use of the model OSIC 5.0, a model based on both first principles and empirical rules. This model, developed by SciTech, was developed specifically for the application of UV propagation through the atmosphere and takes into account scattering and absorption in the atmosphere ${ }^{5}$. The source is an axisymmetric point source; the spectral, temporal and aspect-angle dependent intensity of the source can be specified. The code was extended to have imaging capabilities by ONERA. The latter version was used in this paper. Calculations presented in this paper were performed for an atmosphere with default parameter values listed in Table 3 .

The aerosol scattering coefficient corresponds with a visibility (in the visual band) that could be representative of that at some altitude above the surface layer. For rural aerosol, the visibility would be $80 \mathrm{~km}$; for maritime aerosol, the visibility would be about $50 \mathrm{~km}$.

Table 3. Default atmospheric parameters used for calculating the atmospheric transmission and scattering in the examples presented in this paper.

\begin{tabular}{|ll|}
\hline Ozone concentration & $35 \mathrm{ppbv}$ \\
Temperature & $20^{\circ} \mathrm{C}$ \\
Pressure & $1000 \mathrm{mbar}^{-1}$ \\
Aerosol absorption coefficient & $0.006 \mathrm{~km}^{-1}$ in band $270-290 \mathrm{~nm}$ \\
Aerosol scattering coefficient & $0.056 \mathrm{~km}^{-1}(270 \mathrm{~nm})$ to $0.053 \mathrm{~km}^{-1}(290 \mathrm{~nm})$ \\
Molecular absorption coefficient & $0.75 \mathrm{~km}^{-1}(270 \mathrm{~nm})$ to $0.13 \mathrm{~km}^{-1}(290 \mathrm{~nm})$ \\
Molecular scattering coefficient & $0.22 \mathrm{~km}^{-1}(270 \mathrm{~nm})$ to $0.16 \mathrm{~km}^{-1}(290 \mathrm{~nm})$ \\
\hline
\end{tabular}




\section{RESULTS}

\subsection{Plume images}

Figure 1 shows images of the plume for the HTPB-AP-Al propellant, for off-nose angles between $0^{\circ}$ and $90^{\circ}$. The bright region at about $1 \mathrm{~m}$ from the nozzle is the afterburning region, where high temperature causes high $\mathrm{UV}$ emission (which is both chemiluminescence and radiation from aluminium particles). The Mach discs (regions where internal shock structure causes compression and heating of the gases) are also clearly present in the images. Blocking by the missile body is taken into account, as can be observed in the image for nose-on view, where the central black disc represents the missile body.

Figure 2 allows a comparison among the plumes from the four propellants, at off-nose angles between $0^{\circ}$ and $20^{\circ}$. For each propellant, the set of images is scaled to a common maximum. The absence of aluminium results in a smaller plume for the HTPB-AP and HTPB-AP-HB propellants. The temperature of the GAP exhaust gases is so low, that only at about $1 \mathrm{~m}$ behind the nozzle mixing with ambient air results in significant $\mathrm{UV}$ radiance from afterburning. This is shown more clearly in Figure 3, which shows the four plumes at beam-on view. The plumes intensities were scaled individually. The total radiant intensity for the four propellants at side-on view are $0.04 \mathrm{~mW} / \mathrm{sr} / \mathrm{nm}$ (HTPB-AP-HB), 1 $\mathrm{mW} / \mathrm{sr} / \mathrm{nm}$ (HTPB-AP-Al), $0.02 \mathrm{~mW} / \mathrm{sr} / \mathrm{nm}$ (HTPB-AP) and $0.02 \mathrm{~mW} / \mathrm{sr} / \mathrm{nm}$ (GAP); the low-intensity plumes have a total intensity that is only a few percent of that of current aluminised propellants (assuming equal thrust).

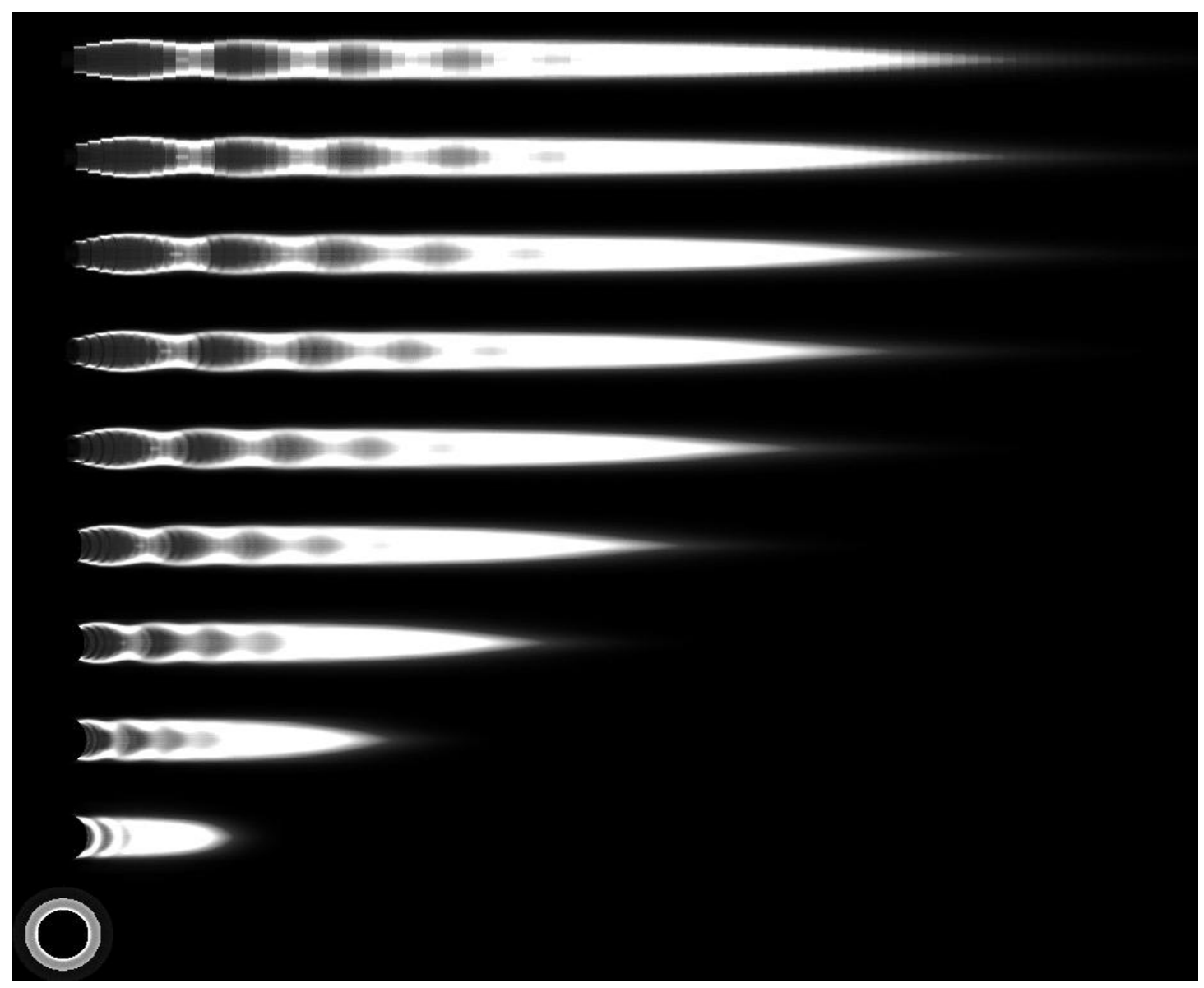

Figure 1: HTPB-AP-Al plumes, at a wavelength of $280 \mathrm{~nm}$, for aspect angles from $0^{\circ}$ (nose-on, bottom) to $90^{\circ}$ (beam-on, top), at intervals of $10^{\circ}$. At nose-on view, most of the plume is blocked by the missile body (the central black disc in the bottom image). The image measures $2 \mathrm{~m}$ in length (horizontal) and $10 \times 16 \mathrm{~cm}$ vertically. The Mach discs can be seen clearly in the images; the bright region at about $1 \mathrm{~m}$ from the nozzle in the plume is a region where afterburning causes high temperatures. 


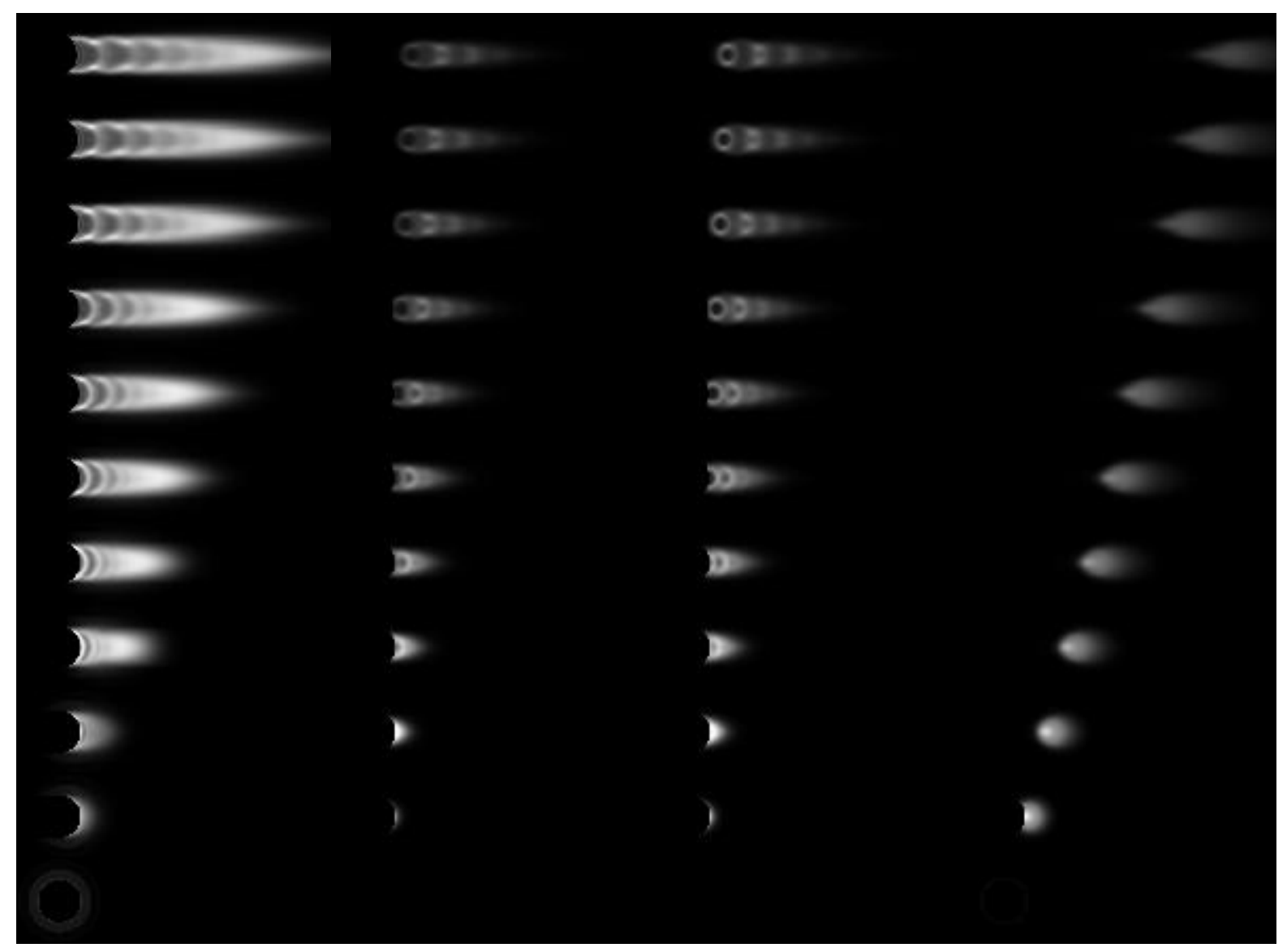

Figure 2: Plume images for near nose-on aspect angles for the four propellants used in this study (from left to right): HTPB-AP-Al, HTPB-AP, HTPB-AP-HB and GAP. Each panel shows the plumes, at a wavelength of $280 \mathrm{~nm}$, for aspect angles from $0^{\circ}$ (nose-on, bottom) to an off-nose angle of $20^{\circ}$ (top), at intervals of $2^{\circ}$. For each propellant, the set of images is scaled to a common maximum. The nozzle is at the left side of each image series; blocking by the missile body is apparent for the HTPB-AP-Al plume (at $0^{\circ}$ off-nose the complete plume is hidden behind the missile body). Setting the total intensity of the HTPB-AP-Al plume at $20^{\circ}$ off-nose to 1 , the total intensities of the HTPB-AP, HTPB-AP-HB and GAP at the same off-nose angle are $0.032,0.047$ and 0.026 , respectively.

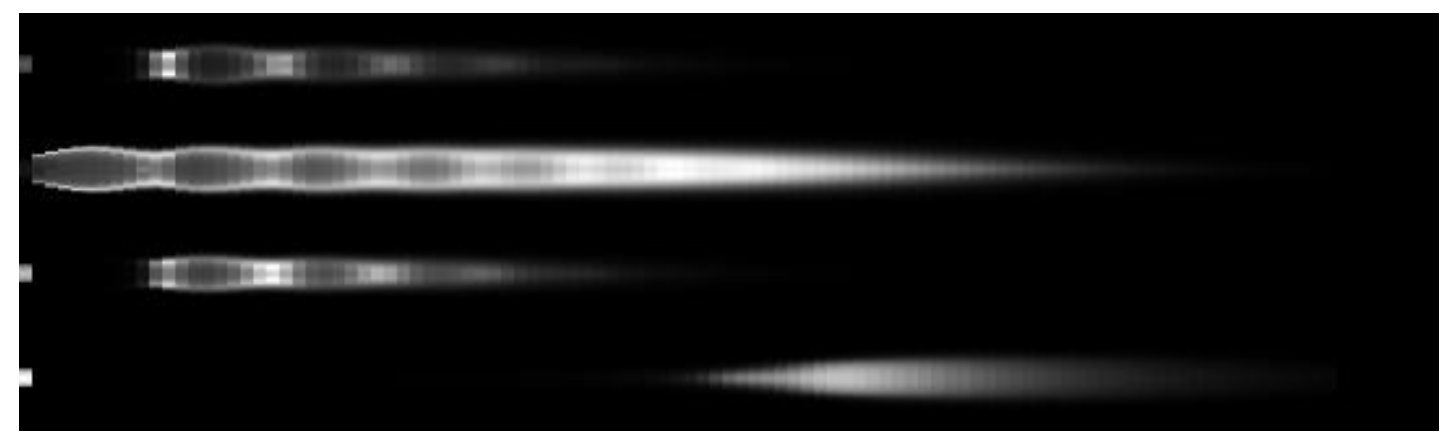

Figure 3. Beam-on images of the plumes for the four propellant types (from top to bottom): HTPB-AP-HB, HTPB-AP-Al, HTPB-AP, GAP. Each plume is scaled separately to allow comparison among the plumes. The image is $2 \mathrm{~m}$ long and $4 \times 16 \mathrm{~cm}$ high. Images were generated for a wavelength of $280 \mathrm{~nm}$. The total radiant intensities of the four plumes are (top to bottom): $0.04 \mathrm{~mW} / \mathrm{sr} / \mathrm{nm}, 1 \mathrm{~mW} / \mathrm{sr} / \mathrm{nm}, 0.02 \mathrm{~mW} / \mathrm{sr} / \mathrm{nm}$ and $0.02 \mathrm{~mW} / \mathrm{sr} / \mathrm{nm}$, at a wavelength of $280 \mathrm{~nm}$. The plumes were computed for a missile velocity of $300 \mathrm{~m} / \mathrm{s}$. Note the GAP plume, which emits UV radiation only in a region far from the nozzle (located at the far left side of the image). The HTPB-AP-Al propellant produces hot gases, that emit UV radiation right from the nozzle. 

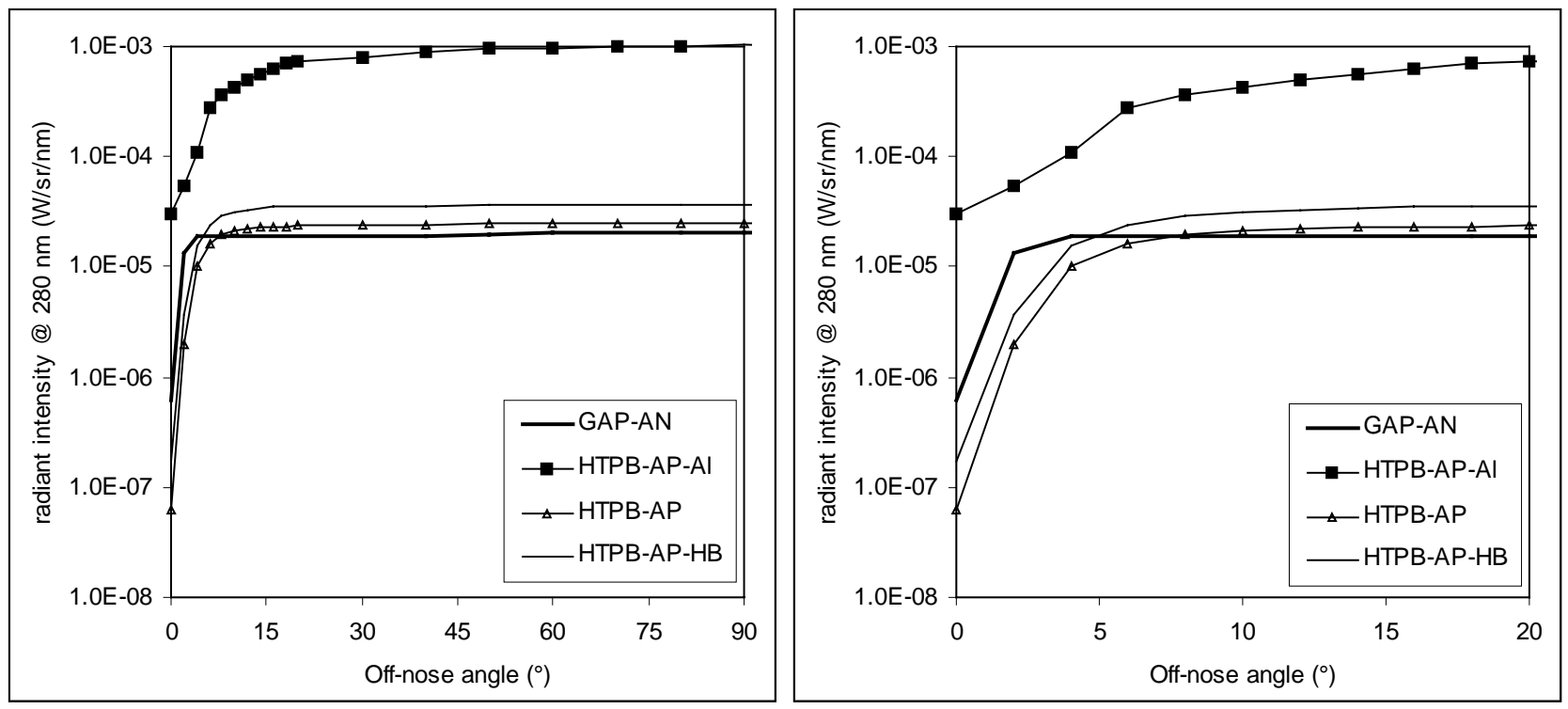

Figure 4. Variation of total radiant intensity of the plumes for the four propellants. Left: off-nose angles from zero to $90^{\circ}$; right: off-nose angles from zero to $20^{\circ}$. The low-intensity plumes show a strong dependence on off-nose angle, due to the fact that most of the plume is hidden behind the missile body at nose-on views. The smaller dependence observed for the HTPB-AP-Al propellants is the result of scattering in the (cold) outer layers of the plume of radiation from the hot core towards the observer (at near nose-on aspects). The latter effect is also known as the search light effect. The GAP-AN propellants produces the lowest-intensity plume, although at near nose-on views the plume is more visible than those of the other low-visibility fuels.

As a further illustration of the different behaviour of the plumes, Figure 4 shows the variation in plume radiant intensity as a function of off-nose angle. The shape and size of the plumes control the increase in radiant intensity. The GAP-AN propellant produces the plume with the lowest total intensity beam-on, but at nose-on aspect the GAP-AN plume is more visible than the HTPB-AP and HTPB-AP-HB plumes. The size of the missile controls how well the plume is hidden behind the missile body; its diameter is set at $8 \mathrm{~cm}$.

The total intensity values given in Figures 1 through 4 are given in units of W/sr/nm, for a wavelength of $280 \mathrm{~nm}$. The value for the sensor wavelength band is found by multiplying by the wavelength band width, $20 \mathrm{~nm}$. Given the relatively narrow band, this is a good approximation of the more exact, but time-consuming way of computing and integrating the plume spectrum.

\subsection{Detection ranges}

The plume images were used to predict the detection ranges for the generic UV sensor. Combining source radiant intensity (dependent on aspect angle), atmospheric propagation (the OSIC model) and the sensor, all the elements in the detection chain are covered. The plume radiant intensity was set not to vary with time. The missile speed was assumed to increase from $0 \mathrm{~m} / \mathrm{s}$ upon launch to its maximum of $500 \mathrm{~m} / \mathrm{s}$ within $3 \mathrm{~s}$ (an eject phase was modelled during the first $0.5 \mathrm{~s}$ ); the burn time was set to $9 \mathrm{~s}$. The missile maintains its maximum speed between $3 \mathrm{~s}$ and $9 \mathrm{~s}$ after launch. This gives a maximum range of the missiles of almost $4 \mathrm{~km}$. These values have not been verified against those for real missiles. The default lay-out of the warning system on the platform consisted of 6 sensors, all with their optical axis on the horizon, distributed evenly over the $360^{\circ}$ in azimuth.

Figure 5 shows polar plots of the detection range against missiles with HTPB-AP-Al (aluminised) and HTPB-AP (nonaluminised) propellants. The HTPB-AP-Al missile is detected upon launch, as is evident from the detection range, which does not vary with threat direction and is equal to the missile range. The much lower intensity of the HTPB-AP plume is reflected in the detection range, which is about $300 \mathrm{~m}$. Note that this gives less than a second between first detection and impact. 

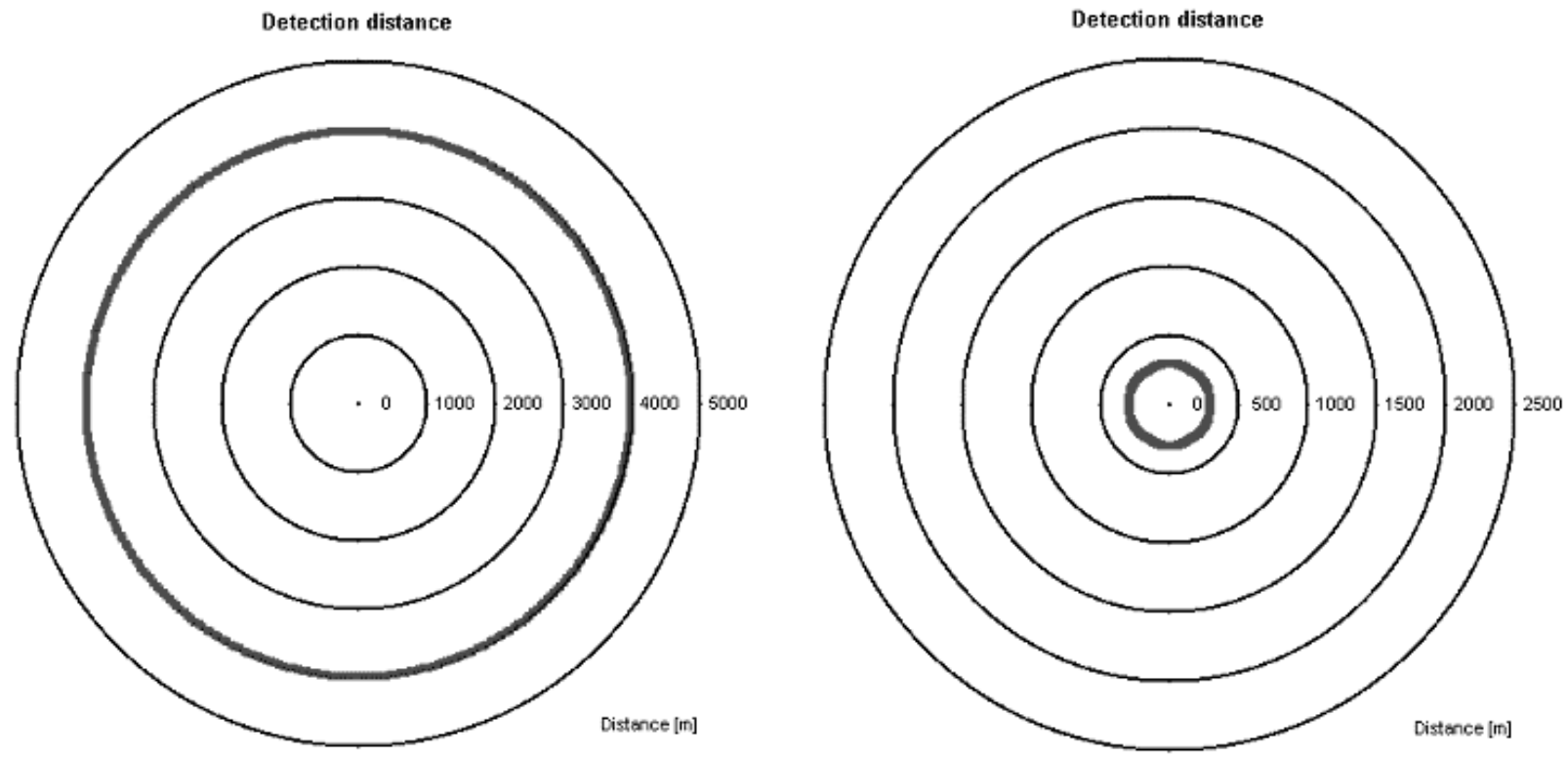

Figure 5. Left: polar plot of detection distance for the generic UV sensor against a missile with HTPB-AP-Al propellant. Right: polar plot of detection distance of a missile with HTPB-AP propellant. Six missile warning sensors, each with FOV of $110^{\circ}$, are aligned with their optical axis on the horizon, pointed at azimuths from $0^{\circ}$ to $300^{\circ}$, at intervals of $60^{\circ}$. The aircraft speed is zero, in both cases. Threat direction $0^{\circ}$ (relative to the aircraft heading) points straight up in the figures.
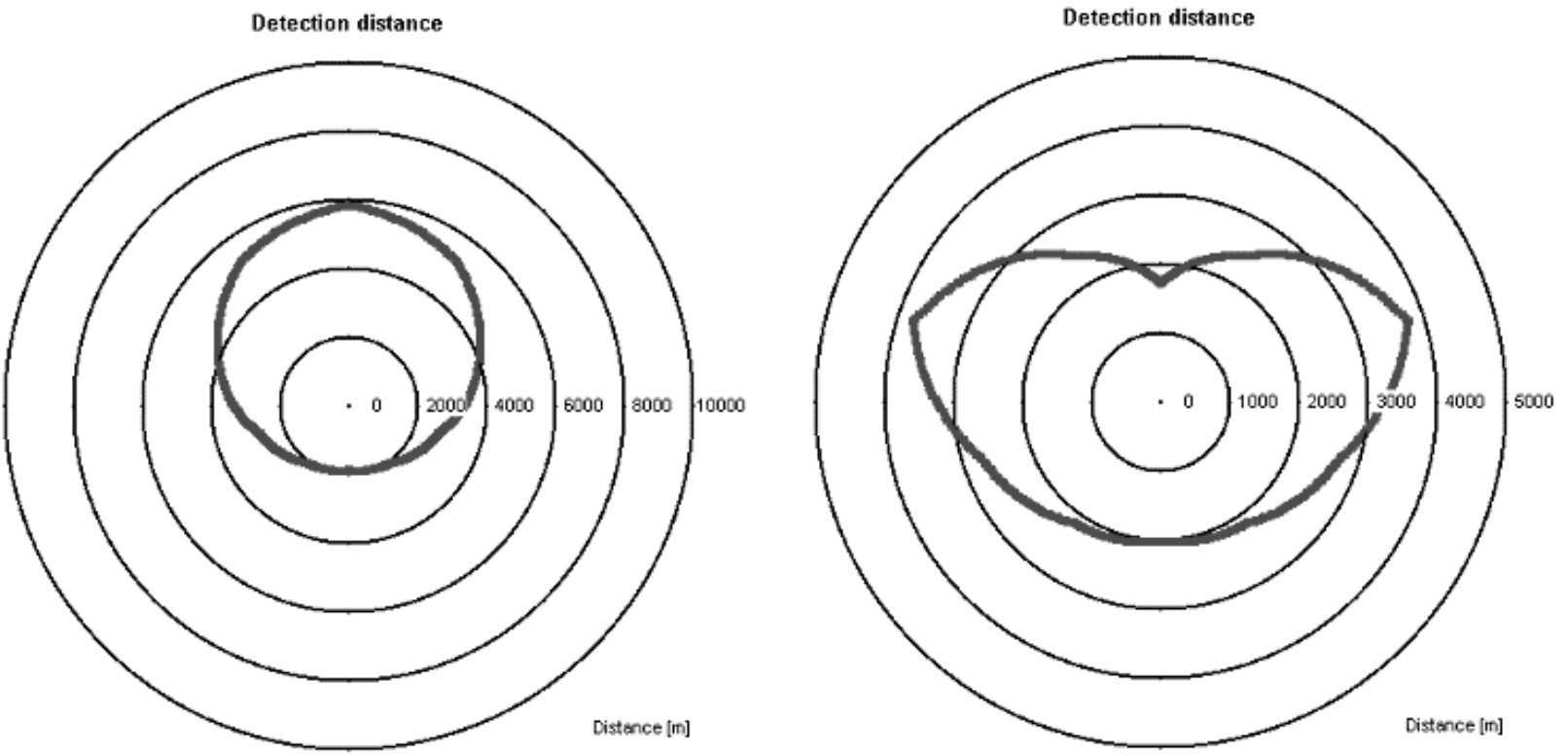

Figure 6. As Figure 5; left: polar plot of detection distance for the generic UV sensor against a missile with HTPB-AP-Al propellant. Right: polar plot of detection distance of a missile with HTPB-AP propellant. The aircraft speed is $250 \mathrm{~m} / \mathrm{s}$, in both cases. Note that as the HTPB-AP plume has low total intensity for near nose-on aspect angles, the detection range for nose-on engagements is quite small, in contrast with the results for the HTPB-AP-Al plume. 


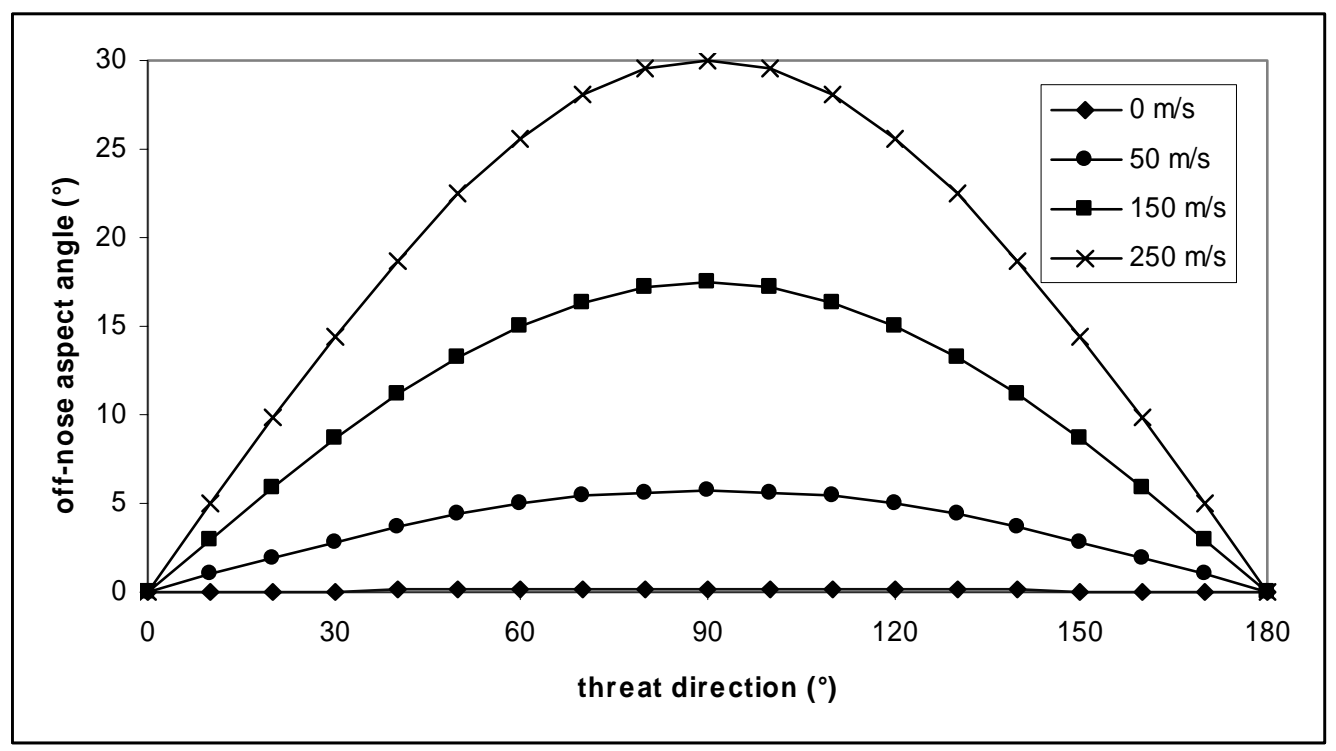

Figure 7: Threat off-nose aspect angle, as seen from its target, as a function of platform velocity. Significant off-nose angles (> $10^{\circ}$ ) occur for target velocities higher than about $100 \mathrm{~m} / \mathrm{s}$. Missile velocity is $500 \mathrm{~m} / \mathrm{s}$.
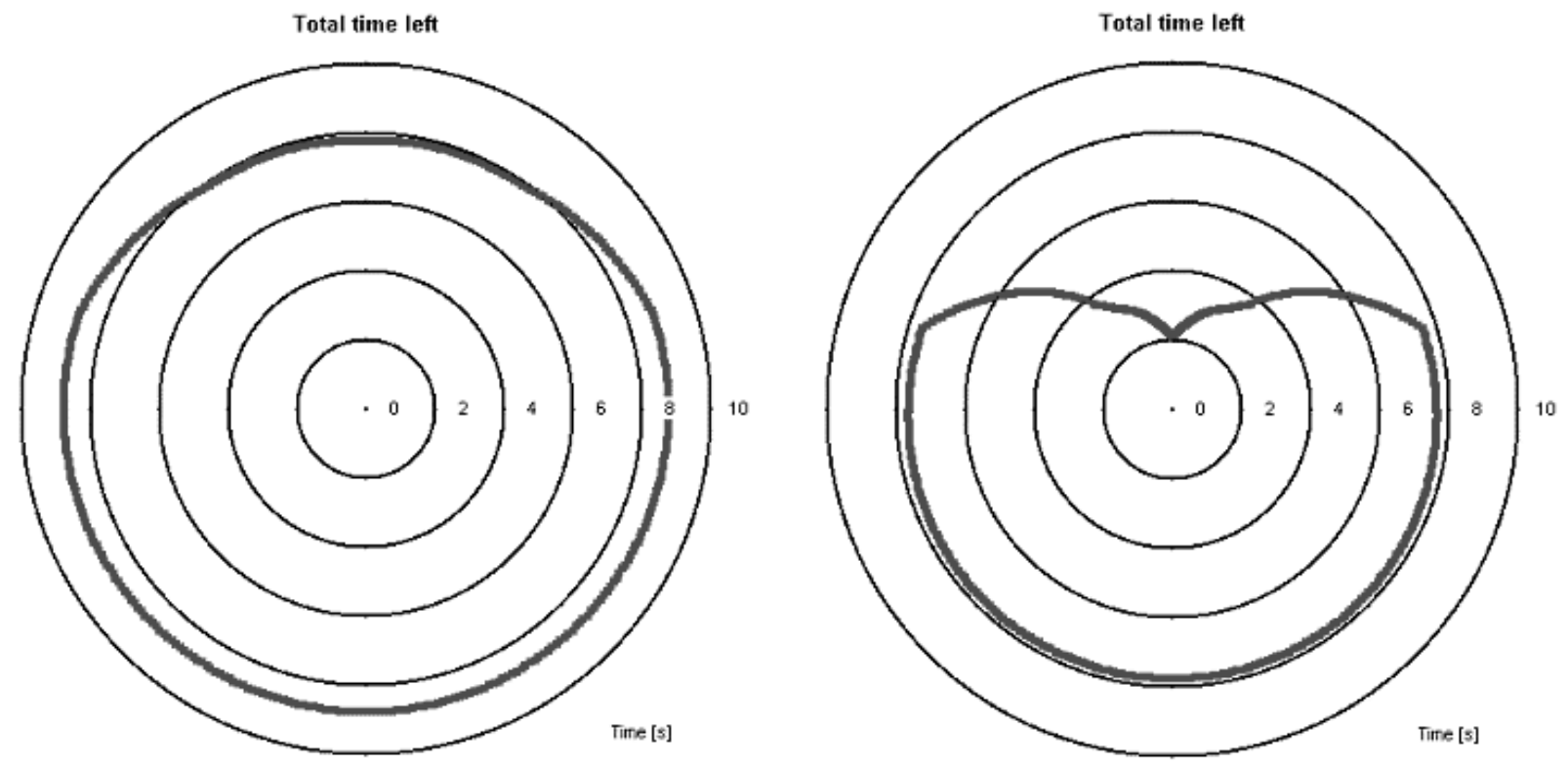

Figure 8. Left: polar plot of time between first detection and impact, for the generic UV sensor against a missile with HTPB-AP-Al propellant. Right: polar plot for a threat with HTPB-AP propellant. The aircraft speed is $250 \mathrm{~m} / \mathrm{s}$, in both cases.

The platform speed used in Figure 5 was zero. The effect of non-zero platform speed can be seen by comparing with the results in Figure 6, that shows detection ranges for an aircraft flying at $250 \mathrm{~m} / \mathrm{s}$. The change in detection distance is most dramatic for the low-intensity plume, which now can be detected from a distance of up to almost $4 \mathrm{~km}$. The reason is that the missile, using proportional navigation, is seen at a non-zero off-nose angle. Figure 4 shows that the visibility of the plume increases rapidly with increasing off-nose angle. The off-nose angle at which a threat is observed, as a function of platform speed, is shown in Figure 7. Assuming proportional navigation and a missile speed of $500 \mathrm{~m} / \mathrm{s}$, the off-nose angle can be derived from the threat direction (relative to the heading of the aircraft). For an aircraft speed of $250 \mathrm{~m} / \mathrm{s}$, the off-nose angle becomes as large as $30^{\circ}$. 
A high aircraft speed also reduces the firing envelope for the missile. For tail-on engagements, the detection range for the HTPB-AP-Al missile is only $2 \mathrm{~km}$, as can be seen from Figure 6 . The time left before impact, however, is still about $9 \mathrm{~s}$, as can be seen from Figure 8, which gives the time interval between first detection and impact for the case shown in Figure 6 (platform speed $250 \mathrm{~m} / \mathrm{s}$ ).

\subsection{Missile warning system lay-out}

The lay-out of the sensors on the aircraft plays an important role in the efficacy of the missile warning system. Optical systems have their highest sensitivity long their optical axis. Off-axis sensitivity is smaller; as most missile warning sensors have large fields of view (FOV), the sensitivity near the edge of their FOV may be significantly lower than that along the optical axis. The dependence of sensor sensitivity on angle of incidence on the optics is modelled here by a cosine law.

Figure 9 illustrates the effects of sensor lay-out on the aircraft. The polar plot in the left of the figure shows time left after first detection for the case where four sensors are aligned with their optical axis on the horizon, at azimuths (relative to the heading of the aircraft) of $0^{\circ}, 90^{\circ}, 180^{\circ}$ and $270^{\circ}$. This results in maximum sensitivity in these directions. For comparison, the case for sensors at $45^{\circ}, 135^{\circ}, 225^{\circ}$ and $315^{\circ}$ is shown in the right panel in the figure. The different lay-out results in longer reaction times at certain azimuths, at the cost of shorter reaction times at, for example nose-on or tail-on engagements.

It should be noted, that next to the total time left for countermeasures, the distances should be considered. For a fast platform, countermeasure (flare) effectiveness depends on the threat distance. At longer distances, flares remain in the threat sensor's field of view longer (depending on the threat direction), which increases the chance of breaking the seeker's lock on the platform. A complete study of platform self-protection would include the seeker properties (e.g., field of view), platform speed, the detection range and the total time left.
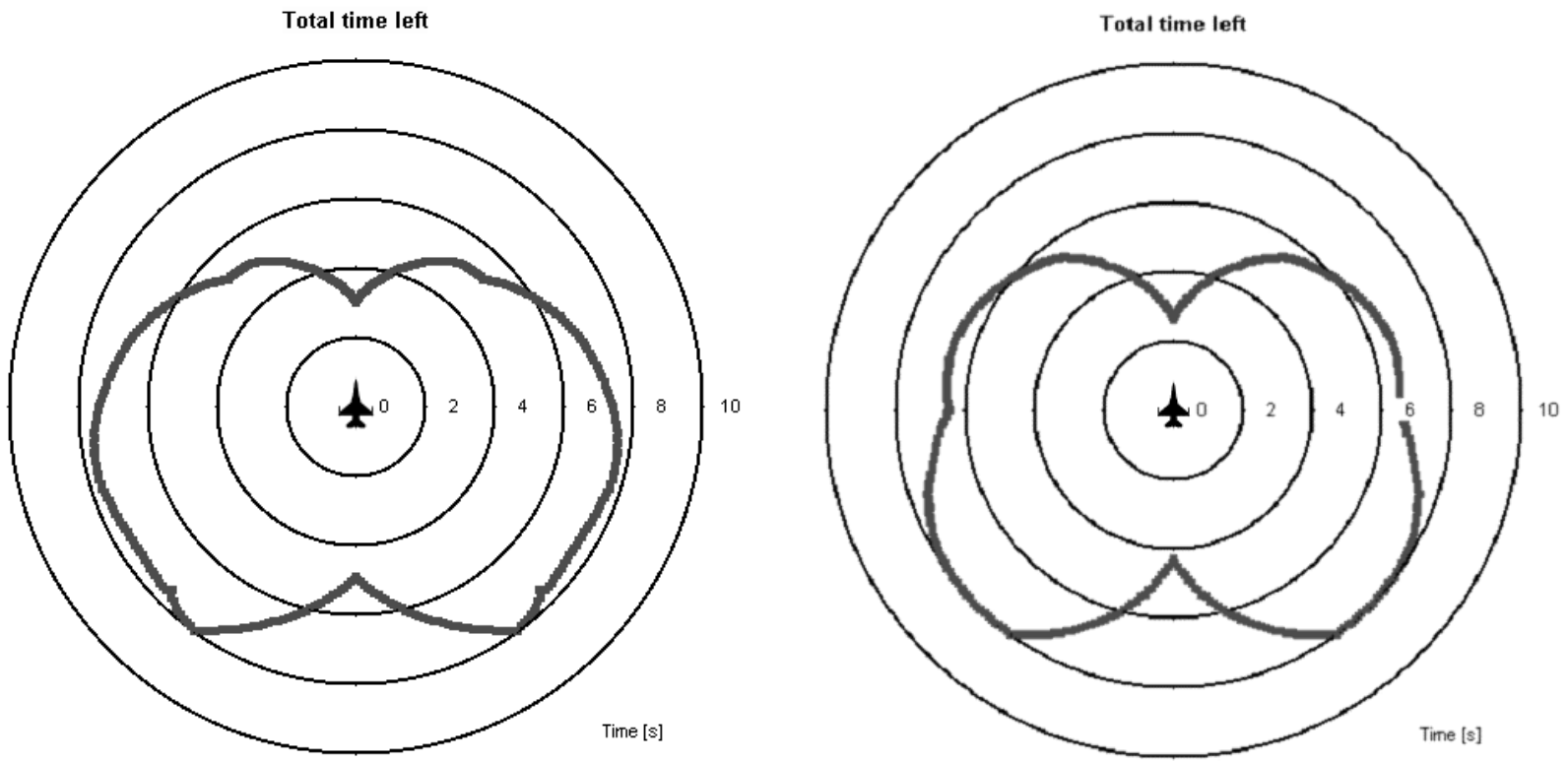

Figure 9: Polar plot of the time between first detection and impact of a HTPB-AP-HB missile, for a platform moving at $100 \mathrm{~m} / \mathrm{s}$. Left: missile warning system lay-out with four sensor oriented at the horizon, at azimuths (relative to the aircraft heading) of $0^{\circ}, 90^{\circ}, 180^{\circ}$ and $270^{\circ}$. Right: four sensors oriented at the horizon, now at azimuths of $45^{\circ}, 135^{\circ}, 225^{\circ}$ and $315^{\circ}$. The different lay-outs result in different levels of self-protection as a function of azimuth. 


\subsection{Amospheric effects}

As atmospheric ozone strongly absorbs both solar and missile plume radiation, its concentration will affect sensor performance. Figure 10 shows the detection range of a HTPB-AP-HB plume, for a stationary platform, as a function of ozone concentration. It is assumed that ozone concentration is constant along the optical path. At a concentration of $300 \mathrm{ppb}$ (which is hazardous to health and can be considered representative of conditions in industrial areas during summer) the detection range is decreased to about $65 \%$ of that during periods with normal ozone concentration (30-50 $\mathrm{ppb})$.

Figure 11 shows the effect of aerosol concentration on the detection range. Whereas all results presented above were obtained with a high visibility (and low aerosol concentration), figure 11 shows the detection range for a missile with HTPB-AP-Al propellant for rural aerosol, with a visibility of $15 \mathrm{~km}$, for both a stationary and fast $(250 \mathrm{~m} / \mathrm{s})$ platform. The higher aerosol concentration results in the detection of the missile at a range of only $2.5 \mathrm{~km}$, for a stationary platform. The results for the fast platform can be compared with those shown in figure 6 (left panel). Differences are found only for head-on engagements; in other directions the limiting factor is missile range, not detection range.

\section{DISCUSSION}

The results shown in this paper prove that the performance of missile warning sensors depends strongly not only on the threat type, but also on platform velocity and weather type. Current threats mostly utilise alumnised propellants, which produce highly visible plumes in the ultraviolet part of the spectrum. However, low-visibility propellants already exist and will be encountered in future operational areas. The current generation of missile warning systems will not be sufficient to ensure aircraft self protection; infared systems, that have a potentially much longer detection range will then be needed to counter the low-visibility threat.

At this point, all elements are available to allow missile warning sensor performance to be evaluated in an operational setting. Tools can be developed to include the level of platform self-protection in mission planning, thus increasing the survivability of both crew and aircraft.

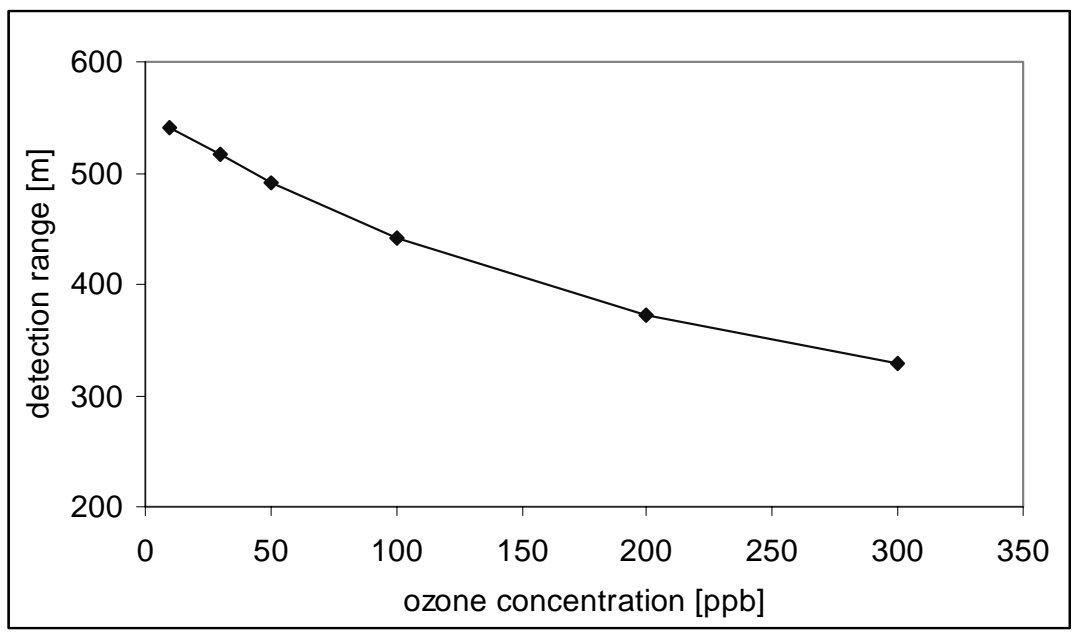

Figure 10: Variation in detection range of a HTPB-AP-HB powered missile, as a function of ozone concentration. Typical ozone concentrations range from 10 to about $50 \mathrm{ppb} ; 300 \mathrm{ppb}$ can be regarded as extreme, occasionally occurring during summer in industrial areas. 

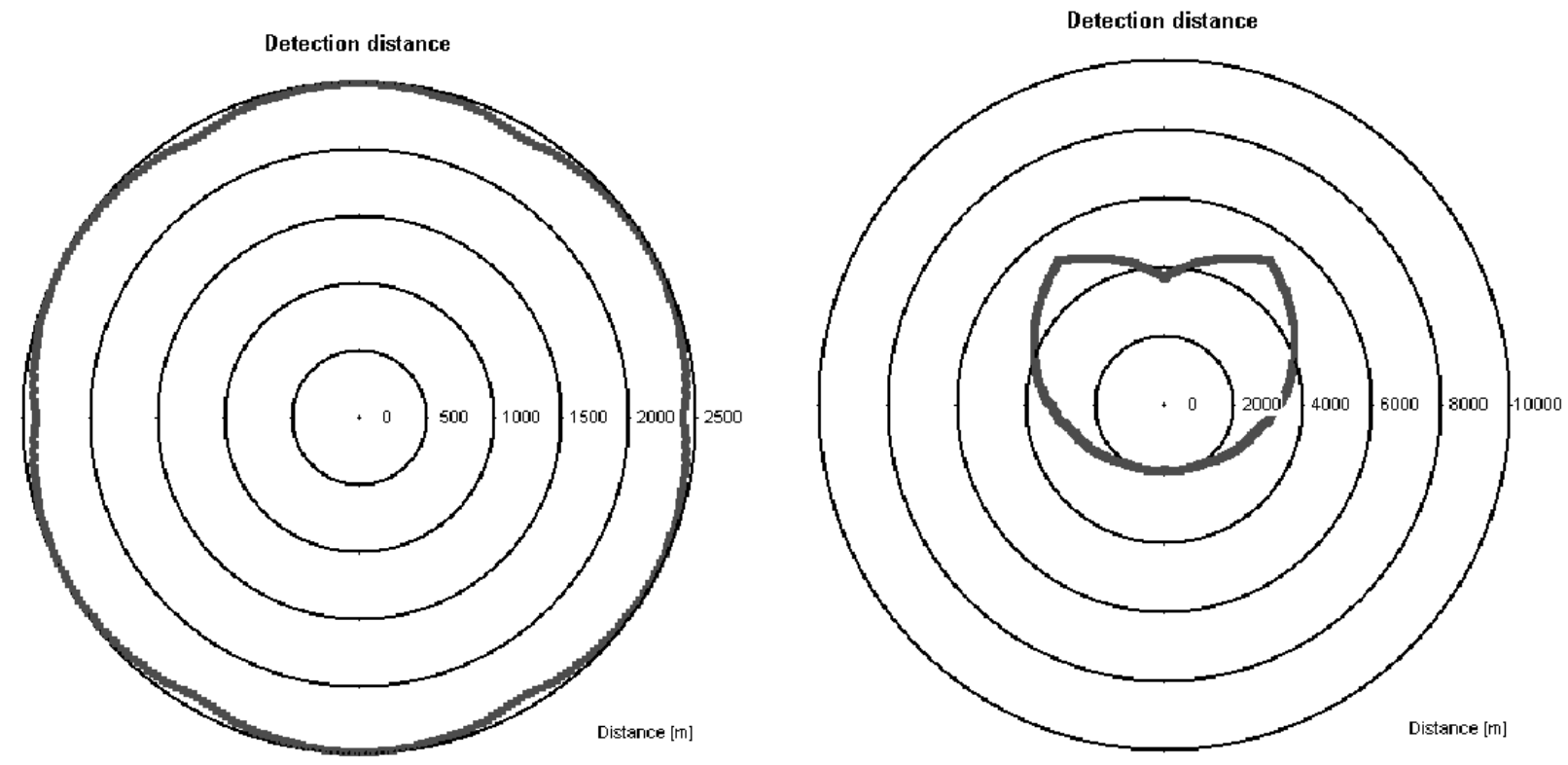

Figure 11: Detection range of a HTPB-AP-Al powered missile, for rural aerosol with a visibility of $15 \mathrm{~km}$. Left: platform speed zero; right: platform speed $250 \mathrm{~m} / \mathrm{s}$. Six missile warning sensors are oriented on the horizon. The left figure should be compared with the left panel in figure 5; the figure on the right should be compared with the left panel in figure 6 .

\section{ACKNOWLEDGEMENTS}

The work described here has been done under contracts from the Royal Netherlands Air Force.

\section{REFERENCES}

1. Neele, F.P. and H.M.A. Schleijpen, UV plume signatures, SPIE Proc. 4718: Targets and backgrounds VIII: characterisation and representation, p. 369-379, SPIE, Orlando, 2002.

2. J. Rapanotti, B. Gilbert, G. Richer and R. Stowe, IR sensor design insight from missile plume prediction models, in: Targets and Backgrounds VIII: characterisation and representation, W.R. Watkins, D. Clement and W.R. Reynolds (eds.), Proc. SPIE, vol. 4718, p. 289-298, 2002.

3. J.M. Cousins, Calculation of conditions in an axi-symmetric rocket exhaust plume: the REP3 computer program, DERA technical report 218, Westcott, United Kingdom, 1982.

4. D.A.B. Fuggle, D.P. Hills, A. Christopher and H. Mace, An efficient procedure for solving the chemical species transport equations in the computer program REP3, DERA technical report 262, Westcott, United Kingdom, 1983.

5. K. Crow, Model description and user's manual, SciTech, Princeton, 1995. 